\title{
Heat evolution of chemically bonded cementitious materials for marine engineering applications
}

\author{
Hailin Cao ${ }^{1 \mathrm{a}}$, Krivenko P.V. ${ }^{2 \mathrm{~b}}$ Luqian Weng $^{1 \mathrm{c}}$, Shaobin Li, Yue Guo ${ }^{1 \mathrm{~d}}$, \\ Petropavlovsky O.N. ${ }^{2 e}$, Pushkar V.I. ${ }^{2 f}$, Kovalchuk A.Yu. ${ }^{2 g}$ \\ ${ }^{1}$ Advanced Materials Research Institute, Shenzhen Academy of Aerospace Technology, \\ Shenzhen, P.R.China \\ ${ }^{2}$ V.D.Glukhovsky Scentific Research Institute for Binders and Materials, Kiev National University of \\ Civil Engineering and Architecture, Kiev, Ukraine \\ acaohl@hit.edu.cn, ${ }^{b, e, f, g}$ pavlo.kryvenko@gmail.com, ${ }^{\circ}$ leeweng@126.com,
guoyuehit@126.com
}

Keywords : chemically bonded cementitious materials, low heat evolution, marine engineering application

Abstract. Chemically bonded cementitious materials possess the high performance properties and excellent durability. They also have a set of special properties, such as low heat evolution. The study focused on the relationship between concrete mix design and heat evolution. On based on the experimental and calculating results, a set of conclusions and guidelines are drawn.

\section{Introduction}

Chemically bonded cementitious materials are produced by activating industrial wastes, particularly slags and fly ashes, therefore, they are environment friendly, and are getting more and more attentions from researchers all over the world. Their high performance properties and excellent durability are recognized by the specialists on building materials and no any additional proofs are required [1]. All this gave a considerable push to the research and development activities with regard to these materials internationally [1-3], in particular, in fast developing countries such as P.R.China [4]. The alkali activated slag cements and concretes are intended for multipurpose use and have big advantages, and are even out of competition especially for making building materials and products to which require a set of special properties, such as low heat evolution.

In order to minimize a risk of crack formation in massive concrete structures due to early-age thermal stresses (heat evolution in concrete), the following requirements in accordance with VSN 31-83 (Ukraine) should be met, these are: temperature gradients are not allowed to exceed; between the middle (further, core) and side surface of a structure in the horizontal direction, further ("horizontal" temperature gradient) $-18^{\circ} \mathrm{C}$; between the core and the upper surface of the structure ("vertical" temperature gradients) $-16^{\circ} \mathrm{C}$; a maximum allowed temperature gradient between the core and the lower (bottom) surface ("vertical" temperature gradient) should be $16{ }^{\circ} \mathrm{C}$; a rate with which the concrete of cast-in-place massive concrete structures is allowed to cool should not exceed $1{ }^{\circ} \mathrm{C} /$ day.

\section{Experimental}

Three concrete mixes varying in content of alkaline activator and presence of fly ash as microfiller have been chosen (Table 1). Chemical compositions of the slag and fly ash used are given in Table 2. 
Table 1 Concrete mixes

\begin{tabular}{|c|c|c|c|}
\hline & №-1 & №-2 & №-3 \\
\hline $\begin{array}{c}\text { GGBS (ground granulated } \\
\text { blast-furnace slag) }\end{array}$ & 352 & 317 & 352 \\
\hline Fly ash & - & 70 & - \\
\hline Sand & 670 & 670 & 670 \\
\hline Coarse aggregate & 1150 & 1115 & 1150 \\
\hline Water & 148,3 & 152 & 160 \\
\hline Activator 1 & 24 & 24 & 32 \\
\hline Activator 2 & 16 & 16 & 8 \\
\hline Watere reducer & 3 & 3 & 3 \\
\hline Density, kg/m3 & 2390 & 2400 & 2400 \\
\hline
\end{tabular}

Table 2 Chemical compositions of the granulated blast-furnace slag and fly ash

\begin{tabular}{|c|c|c|}
\hline \multirow{2}{*}{ Main oxides } & \multicolumn{2}{|c|}{ Quantity, \% by mass } \\
\cline { 2 - 3 } & Slag & Fly ash \\
\hline $\mathrm{SiO} 2$ & 39.4 & 51,61 \\
\hline $\mathrm{S}$ & 1.4 & 0,17 \\
\hline $\mathrm{MgO}$ & 5.19 & 0,82 \\
\hline $\mathrm{A} 2 \mathrm{O} 3$ & 6.8 & 32,31 \\
\hline $\mathrm{MnO}$ & 0.32 & 5,19 \\
\hline $\mathrm{CaO}$ & 47.38 & 6,63 \\
\hline $\mathrm{FeO}$ & 0.32 & \multirow{2}{*}{1,36} \\
\hline $\mathrm{K} 2 \mathrm{O}$ & 0.52 & - \\
\hline $\mathrm{Na} 2 \mathrm{O}$ & 0.6 & \multirow{2}{*}{} \\
\hline $\mathrm{TiO} 2$ & 0.26 & \\
\hline
\end{tabular}

The heat evolution in the concrete mixs was measured with the help of adiabatic calorimeter.

\section{Results and discussion}

The results of heat evolution in the concrete mix №-1 are shown in Fig. 1.

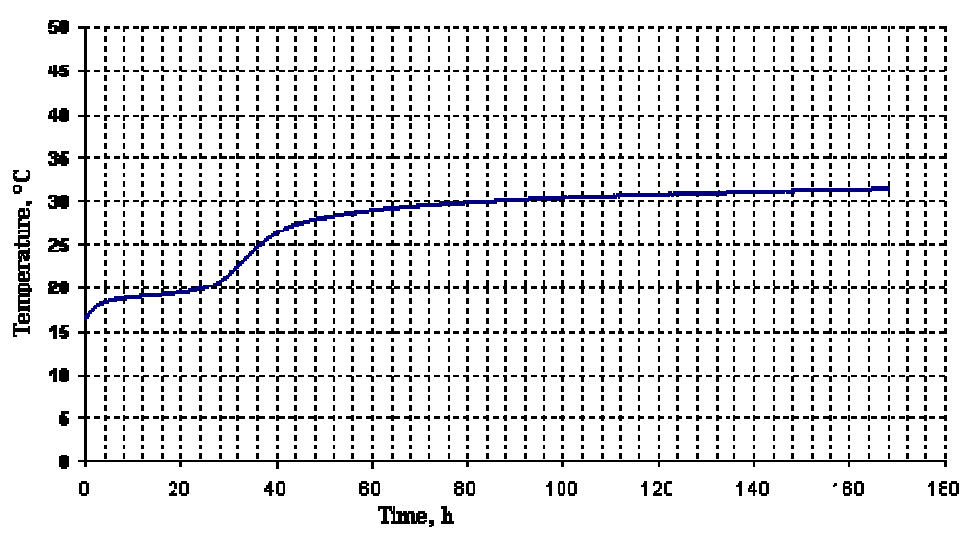

Figure 1. Temperature evolution (concrete mix №-1, Table 1)

Analyzing heat evolution of the concrete mix №-1 suggested to draw the following conclusions: (1)Duration of the induction period reaches $30 \mathrm{hr}$ from the moment when the concrete mix ingredients were mixed with water, then very quick heat evolution starts and proceeds during the phase of structure formation (30-80 hr). When the measurements had been stopped (170 hr) an insignificant temperature rise ( $\sim 1 \mathrm{oC}$ during 2 days) was reported. (2)Self-heating (temperature rise) of the concrete that has been found in the experimental studies corresponds to a cumulative (total) heat of hydration of 
the cement $\mathrm{Q}=107.2 \mathrm{~kJ} / \mathrm{kg}(29.8 \mathrm{~W} / \mathrm{kg})$, thus allowing to classify this cement in accordance with DSTU B V. 2.7-91-99 as a low-heat cement. Basing on the results of experimental studies obtained with the help of adiabatic calorimeter, the coefficients for the below equation (1) have been obtained and the equation was transformed accordingly:

$$
Q(\tau)=Q \cdot\left(1-e^{-0.4^{1.6}}\right)
$$

Equation 1 - expression used for the modeling of heat evolution with appointed coefficients

Where: $\mathrm{Q}=107.2 \mathrm{~kJ} / \mathrm{kg}(29.8 \mathrm{~W} / \mathrm{kg})$ of the slag alkali activated cement This equation was used to plot a theoretical curve of heat evolution in order to model development of the process in the concrete (Fig. 2).

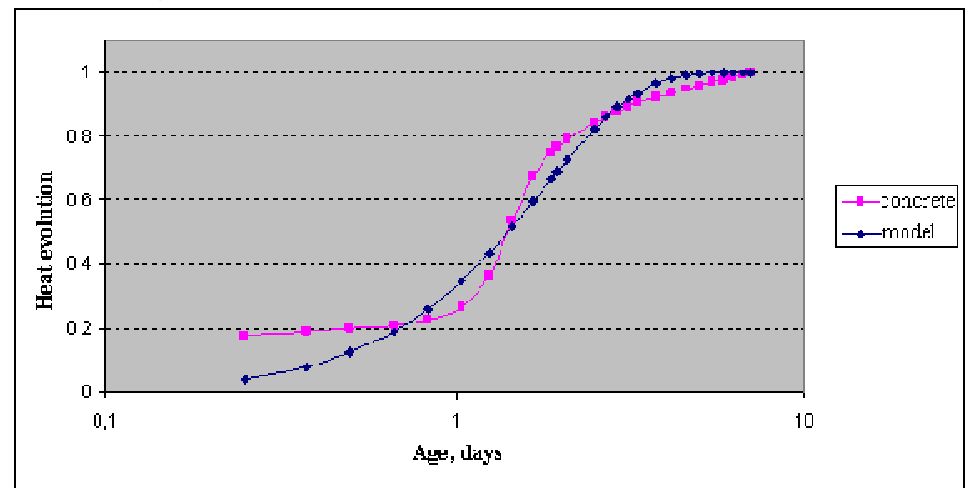

Figure 2. The experimentally plotted curve of heat evolution in the concrete and the theoretical curve (model) describing it

The results of heat evolution in the concrete mix №-2 are shown in Fig. 3.

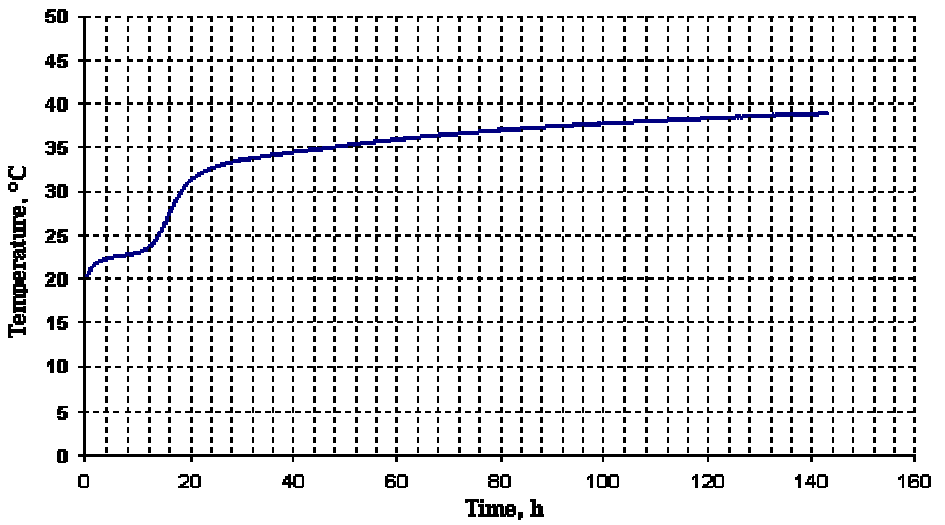

Figure 3. Temperature evolution in the concrete (concrete mix №-2, Table 1)

Analyzing heat evolution of the concrete mix №-2 suggested to draw the following conclusions: (1) Duration of the induction period reaches $12 \mathrm{hr}$ from the moment when the concrete mix ingredients were mixed with water, then the intensive heat evolution starts and proceeds during the phase of structure formation (12-30 hr). When the measurements had been stopped (140 hr) an insignificant temperature rise ( $\sim 10 \mathrm{C} /$ day) was reported. (2)Self-heating (temperature rise) of the concrete that has been found in the experimental studies corresponds to a cumulative (total) heat of hydration of the cement $\mathrm{Q}=107.2 \mathrm{~kJ} / \mathrm{kg}(29.8 \mathrm{~W} / \mathrm{kg})$, thus allowing to classify this cement in accordance with DSTU B V. 2.7-91-99 as a low-heat cement.

Basing on the results of experimental studies obtained with the help of adiabatic calorimeter, the coefficients for the equation (1) have been obtained and the equation was transformed accordingly:

$$
Q(\tau)=Q \cdot\left(1-e^{-0.8^{1.1}}\right)
$$


Equation 2 - expression used for modeling of heat evolution with appointed coefficients

Where: $\mathrm{Q}=121 \mathrm{~kJ} / \mathrm{kg}(33.6 \mathrm{~W} / \mathrm{kg})$ of the slag alkali activated cement.

The produced equation was used to plot a theoretical curve of heat evolution to model development of the process in the concrete (Fig. 4).

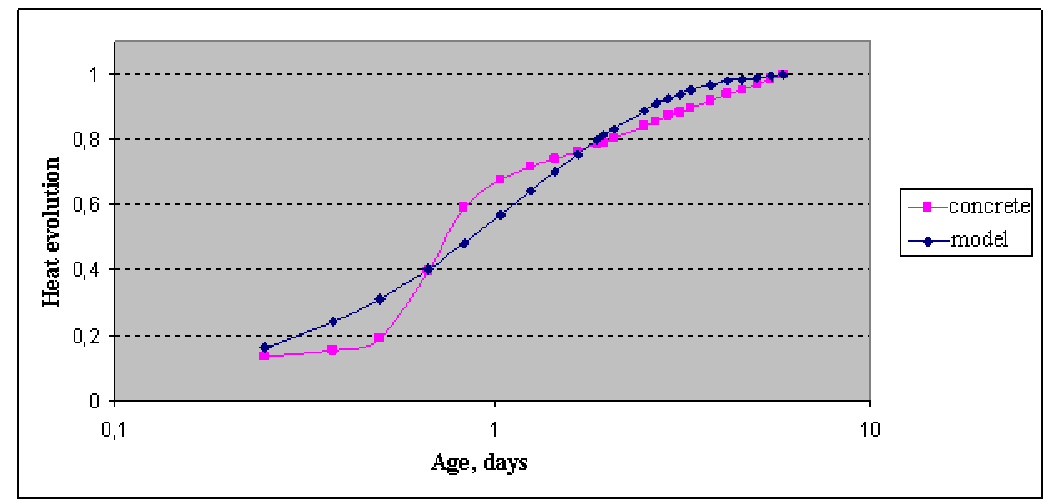

Figure 4. The experimentally plotted curve of heat evolution in the concrete and the theoretical curve (model) describing it

The results of heat evolution in the concrete mix №-3 produced with the help of adiabatic calorimeter are shown in Fig. 5.

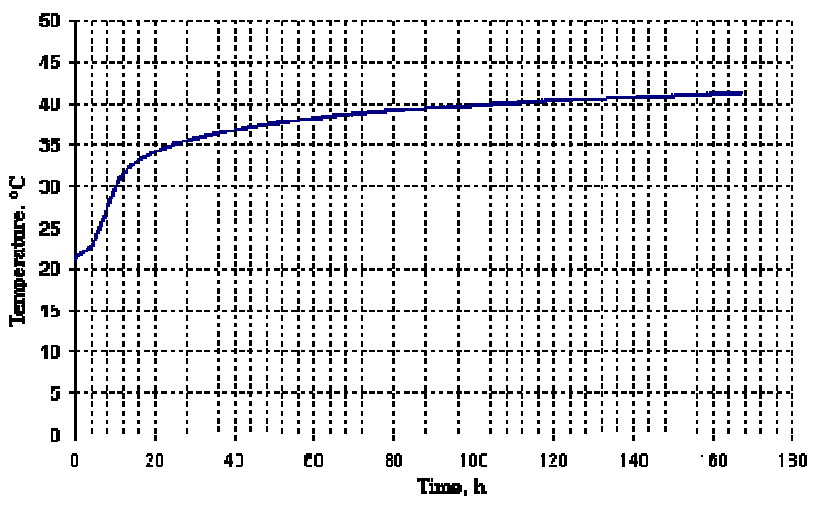

Figure 5 Temperature evolution in the concrete (concrete mix No 3,Table 1)

Analyzing the results of heat evolution in the concrete mix №-3 suggested to draw the following conclusions: (1)Duration of the induction period reaches $12 \mathrm{hr}$ from the moment when the concrete mix ingredients were mixed with water, then the intensive heat evolution starts and proceeds during the phase of structure formation $(5-30 \mathrm{hr})$. When the measurements had been stopped $(160 \mathrm{hr})$ an insignificant temperature rise $\left(\sim 0.5^{\circ} \mathrm{C} /\right.$ day $)$ was reported. (2)Self-heating (temperature rise) of the concrete established experimentally corresponds to a cumulative (total) heat evolution of the cement $\mathrm{Q}=145 \mathrm{KJ} / \mathrm{kg}(40.2 \mathrm{~W} / \mathrm{kg})$, thus allowing to classify this cement, in accordance with DSTU B.V. 2.7-91-99, as a low-heat cement.

Basing on the results of experimental studies obtained with the help of adiabatic calorimeter, the coefficients for the equation (1) have been obtained and the equation was transformed accordingly:

$$
Q(\tau)=Q \cdot\left(1-e^{-1^{\cdot \tau} 0.9}\right)
$$

Equation 3 - expression used for the modeling of

heat evolution with appointed coefficients

Where: $\mathrm{Q}=145 \mathrm{~kJ} / \mathrm{kg}(40.2 \mathrm{~W} / \mathrm{kg})$ of the slag alkali activated cement 
The produced equation was used to plot a theoretical curve of heat evolution to model development of the process in the concrete (Fig. 6).

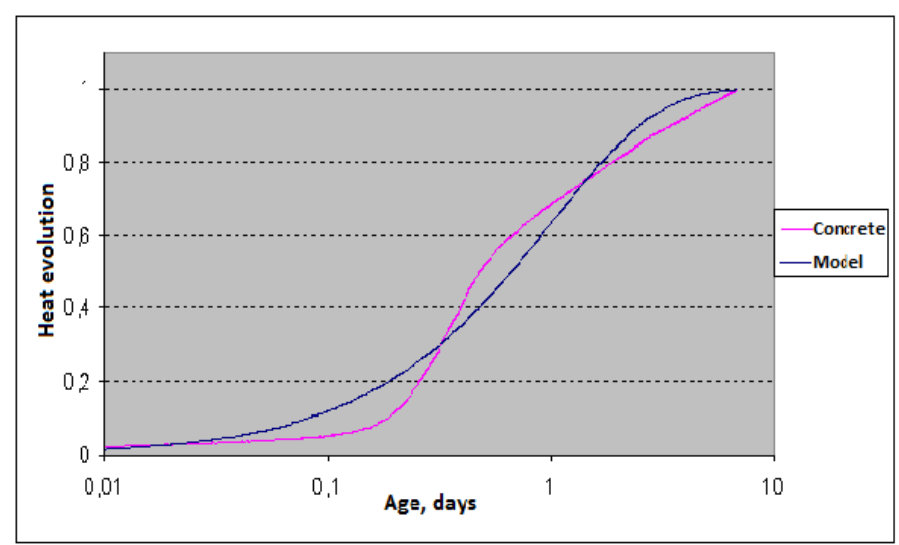

Figure 6 The experimentally plotted curve of heat evolution in the concrete and a theoretical curve (model) describing it

\section{Conclusions}

Analysis of the study of a heat evolution of the chemically bonded cementitious materials allowed to drawn some conclusions. Since, on the contrary to Portland cement concrete, a temperature of the slag alkali activated cement concrete during 7 days rises no more than $20^{\circ} \mathrm{C}$ from the initial temperature of a concrete mix, but the temperature continues to rise at a rate of $0.5-1{ }^{\circ} \mathrm{C} /$ day and after 7 days of hardening, in order to minimize temperature to which the concrete of the structure can be heated, it is recommended to provide its hardening without insulation. With taking into account heat evolution in the concrete, it is recommended to take measurements of temperature of the concrete at least once per day during the first 7 days of hardening and at least once during 2 days, starting from the $8^{\text {th }}$ day and until the insulation is removed. In order to minimize "splitting cracks" occurring while cooling due to restrains applied due to the limiting of concrete by the base plate, as well as due to its shrinkage deformation, it is required to design an adequate quantity of movement joints.

\section{Acknowledgements}

This work was financially supported by the "Special funds for innovative and entrepreneurial talents of high level overseas talents in Shenzhen" (KQTD201208, Shenzhen Municipal Science And Technology Innovation Committee).

\section{References}

[1] Pavel V. Krivenko. Alkaline cements and concretes /Proceed. Second International Conference held at the V. D. Glukhovsky Scientific Research Institute of Binders and Materials in Kiev, Ukraine on 18-20 May, 1999.

[2] Caijun Shi, Pavel V. Krivenko, Della Roy. Alkali-Activated Cements and Concretes. 2006. Taylor \& Francis Group.

[3] Xu Hua, Provis J.L., Deventer Jannie S.J., Krivenko P.V. Characterization of Aged Slag Concretes. ACI Materials, March-April, 2008.- P.131-139.

[4] Pu Xincheng et al. Researches on durability of alkali activated slag concrete, Journal Concrete, No 5, 1991 (in Chinese). 